\title{
Evaluating Treatment Patterns of Gastrointestinal Stromal Tumors in the Elderly and Predicting Outcomes by a Validated Model: A Population- based Study
}

\section{Si Zhao}

Nanjing Medical University Second Affiliated Hospital

Hanlong Zhu

Nanjing Medical University Second Affiliated Hospital

Xiuhua Zhang ( $\square$ 1129wy@sina.com )

Nanjing Medical University Second Affiliated Hospital https:// orcid.org/0000-0003-1580-4768

\section{Primary research}

Keywords: elderlygastrointestinal stromal tumors, treatment patterns, SEER, nomogram, OS

Posted Date: July 2nd, 2020

DOI: https://doi.org/10.21203/rs.3.rs-39530/v1

License: () (i) This work is licensed under a Creative Commons Attribution 4.0 International License.

Read Full License 


\section{Abstract}

Background: Data on the management and outcome of gastrointestinal stromal tumors (GISTs) in elderlypatients are scant due to their poor representation in clinical trials.

Methods:In total, 1379 elderly patients ( $\geq 65$ years) histologically confirmed GIST between2010 and 2016 were enrolled from the Surveillance, Epidemiology, and End Results (SEER) database.

Results: As a result,surgery alone was the predominant treatment used in both age groups. Patients aged $\geq 75$ years who underwent surgery alone had a median survival of 69 months, chemotherapy alone 51 months, surgery plus chemotherapy 60 months, and no therapy 51 months. While among patients aged 65-74 years, the median OS was not reached (NR), 49, 83, and NR, separately. Besides, C-indexes for the OS nomogram in the training set and validation set were 0.771 and 0.761 , respectively. Of importance, the predictive model displayed a comparable result to the 8th American Joint Committee on Cancer TNM staging system ( $\mathrm{p} \otimes 0.05)$, demonstrating improved model discrimination.

Conclusions: For elderly patients with GISTs, surgery alone or surgery plus chemotherapy seemed feasible and effective, conferring potential survival benefits even in very elderly patients. Moreover, this simple-touse nomogram may assist clinicians in treatment decision-making and effectively predict 3-and 5-year survival.

\section{Introduction}

Gastrointestinal stromal tumors (GISTs), originated predominantly from the interstitial cells of Cajal, are seen as widespread mesenchymal tumors of the gastrointestinal tract, with the annual incidence of approximately 11-20 per million worldwide[1-3]. Most GIST patients may harbor functional mutations in the KIT gene and platelet-derived growth factor receptor (PDGFRA), for which up to $30 \%$ of patients have aggressive properties[4]. Although GISTs can occur at any age, they are most commonly found in the population between 60-74 years, which were often poorly represented in clinical trials on cancer treatment, leading to relatively limited information directing the clinical decision[5]. For these reasons, the study about the treatment patterns and its specific outcome for elderly GISTs patients was particularly crucial in this clinical scenario.

Surgeryremains the mainstay therapy for localized or resectable GISTs with a primary purpose of achieving complete resection without positive tumor cell margins and capsule rupture[6]. With the discovery of mutations correlated with GISTs, the treatment has revolutionized dramatically. Imatinib mesylate (IM), as a selective tyrosine kinase receptor inhibitor(TKI), has been widely recommended as adjuvant therapy to improve the mortality and morbidity associated with these tumors, especially for high-risk recurrent or metastatic patients[7]. A previous study has demonstrated that adjuvant treatment with imatinib was given significantly less in high-risk patients with age older than 65 years old[8]. Similarly, compared with the younger counterparts, surgery was also obviously less performed in the elderly, meaning that elderly GIST patients with localized disease were more likely to choose palliative 
therapy or less invasive treatment[9]. Further to this, given the poor physiologic reserves, multiple comorbidities, concurrent medications, and drug resistance in the elderly[10,11], data on the detailed management and outcomes of elderly GISTs patients are scarce. Therefore, the optimal approach for elderly GISTs is still in discussion, which requires to well balance the prognosis of individual patients and their capability to withstand the treatment.

To assist with guiding individualized treatment and clinical practice, accurate predictive models are urgently needed in the elderly GISTs. To date, the TNM staging system from the American Joint Committee on Cancer (AJCC) is commonly utilized to evaluate outcomes of GISTs, whereas other clinicopathological parameters can also influence patient prognosis, such as age, gender, marital status, primary tumor site, and therapy[12, 13]. Of the available decision-making tools, nomogram, as an integrative graphical calculation that incorporates different clinical or laboratory factors to predict specific endpoints by using a statistical model, has been developed in multiple malignancies[14-18]. Although prior studies have reported nomograms in the overall or metastatic populations with GISTs[1921], it is unclear if they are equally applicable to the elderly patients - a population with substantially poorer prognosis.

For such a disease process without sufficient prospective clinical trials, we conducted this study on the basis of the Surveillance, Epidemiology, and End Results (SEER) database, providing more informative and representative evidence. The purpose of our study was to delineate the patterns of treatment in elderly GISTs patients and establisha nomogram topredict overall survival rates.

\section{Patients And Methods}

\section{Ethical statement}

The current study was exempted from the approval of institutional review board since SEER is publicly available for applicants and we have received permission from the SEER program office to access the database (accession number: 18892-Nov 2018).

\section{Database and Patient Selection}

Data of patients diagnosed with GIST were retrospectively obtained from the SEER database between 2010 and 2016. The SEER database is a national collaboration program that contains demographic and clinical information, consisting of 19 regional registries and covering approximately $34 \%$ of the total US population[22]. SEER*Stat 8.3.6 software (National Cancer Institute, Bethesda, MD, USA) was applied tocapture detailed per-patient data. A total of 4615 patients were screened out from the dataset who met the criteria of elderly GISTs patients with the specific histology code (8936, Gastrointestinal stromal tumor) on the basis of the third edition of the International Classification of Diseases for Oncology. Subsequently, eligible patients were included according to the following criteria: (a) age 65 or older at diagnosis; (b) patients with microscopic or histologic confirmation; (c) patientsnot diagnosed at the time of autopsy or death certificate; (d) known survival months and treatment methods including surgery and 
chemotherapy; (e) complete data about mitotic index, primary tumor $(\mathrm{T})$, regional lymph nodes $(\mathrm{N})$, and distant metastasis (M) stage; and (f) patients with one primary tumor. Additionally, patients for whom the follow-up time was less than 1 month were excluded due to the limited immortal time bias[23]. The final analytic cohort was composed of 1379 elderly GIST patients, of which $70 \%$ patients $(n=951)$ were randomly assigned to the training cohort, and the remaining patients $(n=428)$ comprised the validation cohort. Figure 1 shows the detailed process of study selection.

\section{Covariates}

Relevant demographic and clinical variables were involved in our analysis, including age, race, gender, marital status, insurance status, primary tumor site, mitotic index, T, N, and M stage, tumor grade, survival time, vital status record, and treatment characteristics (surgery and chemotherapy). TNM stage was determined by AJCCTNM 7th edition. Considering the same definition for T, N, M in the seventh and eighth editions of AJCC staging, we have reorganized the staging based on the newest AJCC eighth edition, and the decisions concerning recoding were made before modeling. For the aim of maximizing predictive ability, the continuous age variable was transformed into categorical variable (65-74 years and $\geq 75$ years) based on the median age. Similarly, the categorical variables were classified for clinical reasons. The treatment was categorized into four groups: surgery alone, chemotherapy alone, surgery and chemotherapy, and no tumor-directed therapy. Overall survival (OS) was the primary endpoint of interest in our analysis, which was defined as the interval between the date of positive diagnosis and the date of death or the last follow-up.

\section{Construction and validation of the nomogram}

Univariate and multivariate Cox analyses were conducted to screen out survival-associated variables, and an OS nomogram was developed based on the identified independent prognostic variables. Validation of the predictive model was evaluated by measuring discrimination and calibration. The concordance index (C-index) was utilized for discrimination between observed and predicted outcomes, and a higher C-index represented more accurate prognostic estimates. Calibration plots were performed to assess the consistency between predicted probabilities and actual probabilities using a $45^{\circ}$ diagonal line as a perfect model[24]. The prediction regarding the accuracy of survival prognosis between the nomogram and the 8th AJCC TNM staging system were carried out by the area under the receiver operating characteristic (ROC) curve (AUC). Decision curve analysis (DCA) was further applied to evaluate the precision of the nomogram model[25]. Additionally, Kaplan-Meier curves were plotted to analyze the different effect on OS between the high-, middle-, and low-risk groups according to the scores of each patient, which were calculated based on the established Cox regression model.

\section{Statistical analysis}

Descriptive statistics forthe study populationwere reported as count with percentages according to treatment groups. Clinical parameters were evaluated for the training cohortand validationcohort by using chi-square test. A polytomous logistic regression model was performed to assess clinicopathologic 
characteristics associated with treatment receipt, and each treatment category was individually compared with the outcome reference of surgery alone category. The effect of demographic and disease-specific determinants on treatment patternswasdepicted as the adjusted odds ratios (aORs) and95\% confidence intervals (Cls), and OR $>1$ implied higher rate of receiving other treatments except the surgery alone. Survival analysis stratified by age were performed using Kaplan-Meier and log-rank test, and the results were presented as adjusted hazard ratios (HRs) and the corresponding $95 \%$ Cls by utilizing Cox proportional hazards survival models. According to the optimal cut-off value generated by X-tile program, the total points calculated from the nomogram were categorically divided[26]. Survival curves were subsequently delineated in 3 groups of patients with different risk. The following software was applied in the above statistical analysis: SPSS 25.0 (IBM Corp, Armonk, NY) for chi-square test, polytomous logistic regression, Cox regression analyses and random grouping of two cohorts, GraphPad Prism 8.3 (GraphPad Software, San Diego, CA) for survival curves and log-rank test, X-tile software version 3.6.1 (Rimm Laboratory, Yale School of Medicine, New Haven, CT, USA) for the best cut-off value, and R software version 3.3.0 (Institute for Statistics and Mathematics, Vienna, Austria) for nomogram. Statistically significant differences were observed when $p$-value $<0.05$ in a two-sided test.

\section{Results}

\section{Patientsbaseline characteristics and treatment patterns}

A total of 1379 GIST patientsmet the eligibility criteriain this process.Patients' demographic and clinical characteristics across treatment categories aresummarized in Table 1. Of the analyzed patients, $53.0 \%$ received surgery alone, followed by chemotherapy and surgery $(32.2 \%)$, chemotherapy alone $(10.2 \%)$, and no therapy (4.6\%). The majority of cases were white (67.4\%), female (52.5\%), insured (97.0\%), and married $(57.6 \%)$ individuals. Over half of the patients were identified with early-stage AJCC tumors $(50.5 \%)$ and lower mitotic index (73.2\%). Approximately $70.2 \%$ of patients were located in the stomach, with lower prevalence of small intestine (26.3\%) and other sites (3.5\%) including colorectum, esophagus, peritoneum or retroperitoneum, and appendix. In the whole study set, they were far less likely to happen regional lymph node metastasis (3.6\%) and distant metastasis (13.3\%). As to treatment patterns, surgery alone was still the widest choice whatever the age, race, gender, marital and insurance status changed, while patients with $\mathrm{T} 4, \mathrm{~N} 1$, or M1stage tumors more often underwent surgery plus chemotherapy, as well as tumors originated from other sites or with higher mitotic index and grade. In addition, characteristics of the patients in the training cohort $(n=951)$ and validation cohort $(n=428)$ are listed in Table $S 1$, and there were no significant differences observed across the two sets $(P>0.05)$.

\section{Polytomous logistic regression}

The results of the polytomous logistic regression are shown in Table 2. Compared to older counterparts, patients aged $65-74$ years had higher possibility to receive therapy(aOR: $0.415,95 \%$ Cl: $0.235-0.734$ ), and no differences were detected for any of the treatment categories in the light ofgender, race, or insured status. We can also notice that patients with tumor location in the stomach or small intestine were 
connectedwith greater odds of receiving surgeryfor alltreatment categories except surgery plus chemotherapy when compared with tumors located at other sites. Moreover, for all treatment categories, patients without distant metastases were more likely to undergo surgery alone than those with M1 stage tumors (all $p<0.05$ ). Using T4 stage as a reference, patients presented with T2 stage were prone to choose surgery alone, while $\mathrm{T} 1, \mathrm{~T} 3$, and $\mathrm{T} 1$ stage patients, respectively in the combined category and chemotherapy alone category, still had the same choice.

\section{Treatment patterns on survival in different groups}

Survival curves (Figure S1) and corresponding adjusted hazard ratios (Table 3) were presented to describe the results of survival analysisstratified by age acrosstreatment categories, and $P$ values for paired comparison of treatment methods are listed in Table S2. Patients aged $\geq 75$ years who underwent surgery alone had a median survival of 69 months, chemotherapy alone 51 months, surgery plus chemotherapy 60 months, and no therapy 51 months. While among patients aged 65-74 years, the median OS was not reached (NR), 49, 83, and NR, respectively. The adjusted HRs further revealed that chemotherapy alone had a remarkably higher risk of death than those receiving surgery alone (HR: 2.773, $95 \% \mathrm{Cl}: 1.451-5.299, \mathrm{P}=0.002)$, while patients receiving no therapyled to a poor survival compared with the surgery alone group for patients more than 75 years old (HR: 2.075, 95\% Cl: 1.136-3.793, P=0.018).

\section{Univariate and multivariate analysis for OS}

Univariate and multivariate analyses were performed to identify predictors of survival among the 951 patients in the training set. As shown in Table 4, the univariate analysis demonstrated that except for the race and T stage, all other variables were remarkably associated with OS $(P<0.05)$. Then, factors with $\mathrm{P}<0.10$ were further entered into the multivariable model, and we can find that age, gender, marital status, insurance status, location, T stage, $M$ stage, mitotic index, and treatment were recognized as significant independent prognostic factors for elderly GIST patient survival $(P<0.05)$.

\section{Construction and validation of the predictive model}

Figure 2 displays the nomogram to predict 3- and 5-year OS. The C-indexes for OS prediction in the training set and validation set were 0.771 (95\% Cl: 0.734-0.808) and 0.761 (95\% Cl: 0.710-0.812), respectively, indicating more accurate ability in prognosis predicting. Of importance, the calibration plots revealed that the predicted 3- and 5-year OS were in excellent agreement with actual survival in both the training cohort and validation cohort (Figure 3). In addition, the integrated AUC for nomogram showed more powerful efficacy of discrimination in survival prediction compared with that of AJCC TNM 8th edition (nomogram: 0.775 vs $0.638 \mathrm{P}<0.001$ and 0.748 vs $0.670 \mathrm{P}=0.032$, respectively for training and validation cohorts, Figure 4). We also conducted a DCA, and results illustrated that applying this nomogram to predict 3-year and 5-year OS would be better than the newest TNM stage (Figure S2), suggesting greater net benefits (i.e. higher clinical applicability) in this predictive model. Furthermore, we obtained the optimal cut-off value determined by the X-tile program for the two cohorts. In the training set, patients were divided into low-risk group ( $n=428$, median OS: not reached), middle-risk group $(n=355$, 
median OS: 81 months), and high-risk group ( $n=168$, median OS: 38 months), which was similar in the validation set (median OS: not reached, 66 months, and 40 months, respectively). The Kaplan-Meier curves in both cohorts showed significant differences $(P<0.05$, Figure5), indicating that patients who presented with lower risk had a stronger correlation with the reduction of overall death.

\section{Development of webserver}

Additionally, in order to make it easier for clinicians and researchers to predict the survival probability of individual patients, we developed a more accurate web calculator, which was available at https://sizhao.shinyapps.io/elderly_gist/ (Figure S3). By inputting relevant clinical features, the online version of our nomogram can generate corresponding figures and tables, avoiding errors caused by manual measurement.

\section{Discussion}

GISTs occur mainly in the older-aged group population with a reported median age of 65 years and high prevalence at the age of 70 years and older[5]. Currently, with the introduction of TKI, various treatment strategies have been investigated to ameliorate the survival duration of GISTs patients, such as operative intervention, adjuvant targeted therapy, surgery combined with chemotherapy, or supportive care. Nevertheless, treatment decisions may be greatly influenced by age, in part, as a result of the augmented incidence of comorbidities and progressive decline of function correlated with aging[11, 27]. Although there are small numbers of analyses focusing on the treatment of older GISTs patients, these reports consisted of limited patients (18-139 cases) and incomplete treatment categories[28-30]. To our knowledge, this study represents the first attempt to comprehensively depict patterns of treatment and a nomogram for individualized among a population-based analysis of elderly GISTs patients.

In our review, we indeed found that surgery was the predominant treatment used in both age groups and no therapy was the least. Interestingly, however, our logistic regression results demonstrated that patients aged 75 years or above tended to receive supportive care compared to younger individuals. It seemed very elderly populations were relatively conservative in choosing invasive treatments, which might be attributed to declined cardiopulmonary function, reduced tolerance, frailty, and malnutrition in those patients[27]. Moreover, in our cohort of patients older than 75 years, patients without therapy had increased odds of death compared with these of undergoing surgery alone or receiving combined therapy according to our survival analysis and paired $p$ values, suggesting that surgery or combined therapy as positive options may not be discarded among the selected patients. This is in accordance with earlier previous observation showing that lack of treatment could be the reason for their worse survival in elderly patients[31]. Meanwhile, Tham et al. have proposed thatage alone might not deter the optimal management in patients with GISTs[28]. In fact, with the increasing life-expectancy of the elderly, it has been reported that patients over 75 years old have an average life expectancy of up to 12 years[9]. Hence, it is not difficult to understand even in this age group, active surgery and combined treatment might be 
feasible and beneficial. Simultaneously, more efforts with high-quality prospective clinical trials are required to be made to confirm our findings.

As expected, a similar trend was observed in patients aged 65-74 years, of whom cases with surgery alone or combined therapy contributed to a better prognosis. Despite previous findings have revealed significant benefits from adjuvant therapy[9,32], as for the discrepancy that patients treated with chemotherapy alone did not derive survival benefit, this is partly because localized GISTs in this subgroup accounted for $87 \%$ in which surgery inclined to provide a clear survival advantage compared to chemotherapy alone[33]. Of importance, in our present study, treatment patterns, perceived as an independent predictor of OS, further manifested the durable improvement in survival of surgery and combined therapy. Presumably, one possible explanation was that our surgery category included a certain amount of minimally invasive techniques, like endoscopic and laparoscopic resection, which were frequently utilized in real-world practice. This might be an alternative for the elderly who are deemed not tolerated to open laparotomy, and its safety and effectiveness have been acknowledged by prior reports, even for elderly patients with poor performance status[34,35]. Appropriately, consistent with National Comprehensive Cancer Network (NCCN) guidelines[36], patients without distant metastasis or with low mitotic index had a tendency of receiving surgery in our cohort. Moreover, primary tumor site, tumor size, as well as grade were associated with the choice of treatment methods.

Except for treatment patterns, patient age also showed a high association with OS. As previously shown, our findings were supported by Kramer et al. who elucidated that older age was an adverse and independent prognostic factor in GIST patients[32]. In contrast, a prior publication implied a similar survival outcome achieved between younger and older ones[28]. The reason for this divergence was due to the clinical endpoint RFS (recurrence free survival) and PFS (progression free survival) used by the latter. Furthermore, in line with several published reports[31, 37, 38], we identified gender, marital and insurance status, location, tumor size, mitotic count, and $\mathrm{M}$ stage as predictive factors of survival for GIST patients. All of these easily ascertainable clinical risk factors were integrated into a concise nomogram model to provide prediction on OS, effectively facilitating the personalized treatment. In spite of a limited number of studies in which nomograms were designed for evaluating the prognosis of GISTs patients existing, none of these studies concentrated on elderly GISTs patients[19-21].

Notably, our nomogram exhibited more excellent predictive ability than the eighth AJCC staging system in the light of AUC analysis ( 0.775 vs $0.638 \mathrm{P}<0.001$ and 0.748 vs $0.670 \mathrm{P}=0.032$, separately for training and validation sets). Discriminatory power and accuracyof the nomogram were further confirmed using C-index and calibration plot with respect to both training and validation cohorts. More importantly, favorable clinical utility was also verified by DCA, which was a novel method for assessing prediction models and diagnostic tests. Further still, we stratified GISTs patients into three risk groups and significant differences in survival were observed among groups in both two cohorts. On the basis of risk stratification, the model can provide evidence for individualized prognostic evaluation and propose an intense surveillance schedule for high-risk patients. Undoubtedly, our nomogram, a practical instrument, 
was extremely feasible and valuable, while the need to replicate and further validate our observations in other well-defined populations, is warranted.

The current research is not devoid of limitations,which are important to better understand our findings in specificpopulations utilizing this database. Firstly, in view of its retrospective nature, one of the main limitations is that patients did not conduct a comprehensive geriatric assessment (CGA) in our analysis, which is a multidisciplinary and interdisciplinary diagnostic procedure focusing on identifying medical, functional and psychosocial capabilities to develop an appropriate and personalized management of elderly cancer patients[39, 40]. It has been recommended to be incorporated into the clinical decision making of elderly GISTs therapy, which is more efficient over the classical assessment of comorbidities in the prediction of survival[41, 42]. Secondly, considering the nonavailability of these information in the SEER database, our model did not contain otherimportant predictive molecular parameters as reported in previous publications, such as the KIT gene, exon mutation as well as the PDGRA mutation[19]. In addition, treatment details were not provided, including the sequence of the treatment, surgical margin status, treatment toxicity, chemotherapy regimens, dose of chemotherapy used, and reasons of patients or physician preferences for treatment, which should be taken into account in future prospective validation. Lastly, potential selection bias on treatment strategies would be inherent due to the nonrandom treatment allocationin the SEER database, so survival analysis might be confounded by factors that alter the possibility of receiving a certain treatment. Thus, we look forward to well-designed prospective randomized clinical trials verifying our results and application of the model.

\section{Conclusion}

In summary, this study suggests surgery was more frequently chose both inGISTs patients of age 65-74 years and age older than 75 years, and surgery alone or surgery plus chemotherapy seemed feasible and effective, conferring potential survival benefits even in very elderly patients. We recommend that the management of elderly patients with GISTs should be individualized by multidisciplinary teams due to the unknown decision-making considerations for treatment in selected patients. In addition, a practical nomogram for accurately predicting 3-year and 5-year OS was developed, which can assist clinicians to guide appropriate treatment for each patient as well as to improve their prognostic assessment. Further external validation by analyzing more comprehensive data, however, is still needed.

\section{Abbreviations}

GISTs: gastrointestinal stromal tumors; PDGFRA: platelet-derived growth factor receptor (PDGFRA)platelet-derived growth factor receptor; IM: Imatinib mesylate, TKI: tyrosine kinase receptor inhibitor; AJCC: American Joint Committee on Cancer; SEER: the Surveillance, Epidemiology, and End Results; T: primary tumor, N: regional lymph nodes, M: distant metastasis; OS: overall survival; C-index: concordance index; ROC: receiver operating characteristic; AUC: area under the curve; DCA: decision curve analysis; aORs: adjusted odds ratios; Cls: confidence intervals; HRs: hazard ratios; NR: not reached; NCCN: 
National Comprehensive Cancer Network; RFS: recurrence free survival; PFS: progression free survival; CGA: comprehensive geriatric assessment.

\section{Declarations}

\section{Contributions}

$\mathrm{SZ}$ and $\mathrm{HZ}$ collected and analyzed the data, wrote the paper; $\mathrm{HZ}$ and $\mathrm{XZ}$ conceived and designed this study. All authors reviewed the paper. All authors read and approved the final manuscript.

\section{Acknowledgments}

We would like to thank the researchers and study participants for their contributions.

\section{Competing interests}

The authors declare that they have no competing interests.

\section{Funding}

Not applicable.

\section{Availability of data and materials}

All data are included in this article.

\section{Ethics approval and consent to participate}

Not applicable.

\section{Consent for publication}

Not applicable.

\section{References}

1. Corless CL: Gastrointestinal stromal tumors: what do we know now?Mod Pathol 2014, 27 Suppl 1:S1-16.

2. Rubin JL, Sanon M, Taylor DC, Coombs J, Bollu V, Sirulnik L: Epidemiology, survival, and costs of localized gastrointestinal stromal tumors. Int J Gen Med 2011, 4:121-130.

3. Corless CL, Fletcher JA, Heinrich MC: Biology of gastrointestinal stromal tumors. J Clin Oncol2004, 22(18):3813-3825.

4. Mucciarini C, Rossi G, Bertolini F, Valli R, Cirilli C, Rashid I, Marcheselli L, Luppi G, Federico M: Incidence and clinicopathologic features of gastrointestinal stromal tumors. A population-based 
study. BMC Cancer 2007, 7:230.

5. Soreide K, Sandvik OM, Soreide JA, Giljaca V, Jureckova A, Bulusu VR: Global epidemiology of gastrointestinal stromal tumours (GIST): A systematic review of population-based cohort studies. Cancer Epidemiol 2016, 40:39-46.

6. lorio N, Sawaya RA, Friedenberg FK: Review article: the biology, diagnosis and management of gastrointestinal stromal tumours. Aliment Pharmacol Ther 2014, 39(12):1376-1386.

7. Parab TM, DeRogatis MJ, Boaz AM, Grasso SA, Issack PS, Duarte DA, Urayeneza O, Vahdat S, Qiao JH, Hinika GS: Gastrointestinal stromal tumors: a comprehensive review. J Gastrointest Oncol 2019, 10(1):144-154.

8. Harlan LC, Eisenstein J, Russell MC, Stevens JL, Cardona K: Gastrointestinal stromal tumors: treatment patterns of a population-based sample. J Surg Oncol 2015, 111(6):702-707.

9. Farag S, van Coevorden F, Sneekes E, Grunhagen DJ, Reyners AKL, Boonstra PA, van der Graaf WT, Gelderblom HJ, Steeghs N: Elderly patients with gastrointestinal stromal tumour (GIST) receive less treatment irrespective of performance score or comorbidity - A retrospective multicentre study in a large cohort of GIST patients. Eur J Cancer 2017, 86:318-325.

10. Raut CP, Gronchi A: Cytoreductive surgery in advanced GIST: timing is everything. Ann Surg Oncol 2013, 20(13):4059-4060.

11. Italiano A, Saada E, Cioffi A, Poulette S, Bouchet S, Molimard M, Adenis A, Isambert N, Collard O, Le Cesne $A$ et al: Treatment of advanced gastrointestinal stromal tumors in patients over $\mathbf{7 5}$ years old: clinical and pharmacological implications. Target Oncol 2013, 8(4):295-300.

12. El-Menyar A, Mekkodathil A, Al-Thani H: Diagnosis and management of gastrointestinal stromal tumors: An up-to-date literature review. J Cancer Res Ther 2017, 13(6):889-900.

13. Li J, Zhang H, Chen Z, Su K: Clinico-pathological characteristics and prognostic factors of gastrointestinal stromal tumors among a Chinese population. Int J Clin Exp Pathol 2015, 8(12):15969-15976.

14. lasonos A, Schrag D, Raj GV, Panageas KS: How to build and interpret a nomogram for cancer prognosis. J Clin Oncol 2008, 26(8):1364-1370.

15. Liang W, Yang P, Huang R, Xu L, Wang J, Liu W, Zhang L, Wan D, Huang Q, Lu Y et al: A Combined Nomogram Model to Preoperatively Predict Histologic Grade in Pancreatic Neuroendocrine Tumors. Clin Cancer Res 2019, 25(2):584-594.

16. Dong D, Tang L, Li ZY, Fang MJ, Gao JB, Shan XH, Ying XJ, Sun YS, Fu J, Wang XX et al: Development and validation of an individualized nomogram to identify occult peritoneal metastasis in patients with advanced gastric cancer. Ann Oncol 2019, 30(3):431-438.

17. Wang X, Mao M, He Z, Zhang L, Li H, Lin J, He Y, Dai S, Hu W, Liu W: Development and Validation of a Prognostic Nomogram in AFP-negative hepatocellular carcinoma. Int J Biol Sci 2019, 15(1):221-228.

18. Sun XS, Liang YJ, Jia GD, Liu SL, Liu LT, Guo SS, Sun R, Luo DH, Chen QY, Tang LQ et al:

Establishment of a prognostic nomogram to identify optimal candidates for local treatment among patients with local recurrent nasopharyngeal carcinoma. Oral Oncol 2020, 106:104711. 
19. Chen Z, Lin RM, Bai YK, Zhang Y: Establishment and Verification of Prognostic Nomograms for Patients with Gastrointestinal Stromal Tumors: A SEER-Based Study. Biomed Res Int 2019, 2019:8293261.

20. Song W, Lv CG, Miao DL, Zhu ZG, Wu Q, Wang YG, Chen L: Development and validation of a nomogram for predicting survival in patients with gastrointestinal stromal tumours. Eur J Surg Oncol 2018, 44(10):1657-1665.

21. Lee CK, Goldstein D, Gibbs E, Joensuu H, Zalcberg J, Verweij J, Casali PG, Maki RG, Cioffi A, McArthur $\mathrm{G}$ et al: Development and validation of prognostic nomograms for metastatic gastrointestinal stromal tumour treated with imatinib. Eur J Cancer 2015, 51(7):852-860.

22. Surveillance, Epidemiology, and End Results Program Overview. https://seer.cancer.gov/about/factsheets/SEER_Overview.pdf. Accessed 28 Feb 2019.

23. Park HS, Gross CP, Makarov DV, Yu JB: Immortal time bias: a frequently unrecognized threat to validity in the evaluation of postoperative radiotherapy. Int J Radiat Oncol Biol Phys 2012, 83(5):1365-1373.

24. Wolbers M, Koller MT, Witteman JC, Steyerberg EW: Prognostic models with competing risks: methods and application to coronary risk prediction. Epidemiology 2009, 20(4):555-561.

25. Fitzgerald M, Saville BR, Lewis RJ: Decision curve analysis. JAMA 2015, 313(4):409-410.

26. Camp RL, Dolled-Filhart M, Rimm DL: X-tile: a new bio-informatics tool for biomarker assessment and outcome-based cut-point optimization. Clin Cancer Res 2004, 10(21):7252-7259.

27. Denewet N, De Breucker S, Luce S, Kennes B, Higuet S, Pepersack T: Comprehensive geriatric assessment and comorbidities predict survival in geriatric oncology. Acta Clin Belg 2016, 71(4):206213.

28. Tham CK, Poon DY, Li HH, Tan MH, Choo SP, Foo KF: Gastrointestinal stromal tumour in the elderly. Crit Rev Oncol Hematol 2009, 70(3):256-261.

29. Rutkowski P, Bylina E, Lugowska I, Teterycz P, Klimczak A, Streb J, Czarnecka AM, Osuch C: Treatment outcomes in older patients with advanced gastrointestinal stromal tumor (GIST). J Geriatr Oncol 2018, 9(5):520-525.

30. Molinas Mandel N, Selcukbiricik F, Kanitez M, Yalcin S, Tural D, Erdamar S, Dogusoy G, Demir G: Clinical and pathological characteristics and their effect on survival in elderly patients with gastrointestinal stromal tumors. J BUON2016, 21(2):360-365.

31. Kramer K, Knippschild U, Mayer B, Bogelspacher K, Spatz H, Henne-Bruns D, Agaimy A, Schwab M, Schmieder M: Impact of age and gender on tumor related prognosis in gastrointestinal stromal tumors (GIST). BMC Cancer 2015, 15:57.

32. Muss HB, Biganzoli L, Sargent DJ, Aapro M: Adjuvant therapy in the elderly: making the right decision. J Clin Oncol 2007, 25(14):1870-1875.

33. Etherington MS, DeMatteo RP: Tailored management of primary gastrointestinal stromal tumors. Cancer 2019, 125(13):2164-2171. 
34. Milone M, Elmore U, Musella M, Parise P, Zotti MC, Bracale U, Di Lauro K, Manigrasso M, Milone F, Rosati R: Safety and efficacy of laparoscopic wedge gastrectomy for large gastrointestinal stromal tumors. Eur J Surg Oncol 2017, 43(4):796-800.

35. Yang TC, Hou MC, Chen PH, Hsin IF, Chen LK, Tsou MY, Lin HC, Lee FY: Clinical Outcomes and Complications of Endoscopic Submucosal Dissection for Superficial Gastric Neoplasms in the Elderly. Medicine (Baltimore) 2015, 94(44):e1964.

36. von Mehren M, Randall RL, Benjamin RS, Boles S, Bui MM, Ganjoo KN, George S, Gonzalez RJ, Heslin MJ, Kane JM et al: Soft Tissue Sarcoma, Version 2.2018, NCCN Clinical Practice Guidelines in Oncology. J Natl Compr Canc Netw 2018, 16(5):536-563.

37. Chen $M$, Wang $X$, Wei $R$, Wang Z: The influence of marital status on the survival of patients with operable gastrointestinal stromal tumor: A SEER-based study. Int J Health Plann Manage 2019, 34(1):e447-e463.

38. Jumniensuk C, Charoenpitakchai M: Gastrointestinal stromal tumor: clinicopathological characteristics and pathologic prognostic analysis. World J Surg Oncol 2018, 16(1):231.

39. Balducci L: Management of cancer in the elderly. Oncology (Williston Park) 2006, 20(2):135-143; discussion 144, 146, 151-132.

40. Repetto L, Fratino L, Audisio RA, Venturino A, Gianni W, Vercelli M, Parodi S, Dal Lago D, Gioia F, Monfardini $S$ et al: Comprehensive geriatric assessment adds information to Eastern Cooperative Oncology Group performance status in elderly cancer patients: an Italian Group for Geriatric Oncology Study. J Clin Oncol 2002, 20(2):494-502.

41. Extermann M, Hurria A: Comprehensive geriatric assessment for older patients with cancer. $J$ Clin Oncol 2007, 25(14):1824-1831.

42. Girre V, Falcou MC, Gisselbrecht M, Gridel G, Mosseri V, Bouleuc C, Poinsot R, Vedrine L, Ollivier L, Garabige $V$ et al: Does a geriatric oncology consultation modify the cancer treatment plan for elderly patients? J Gerontol A Biol Sci Med Sci 2008, 63(7):724-730.

\section{Tables}


Table 1

Patients' demographic characteristics according to treatment received.

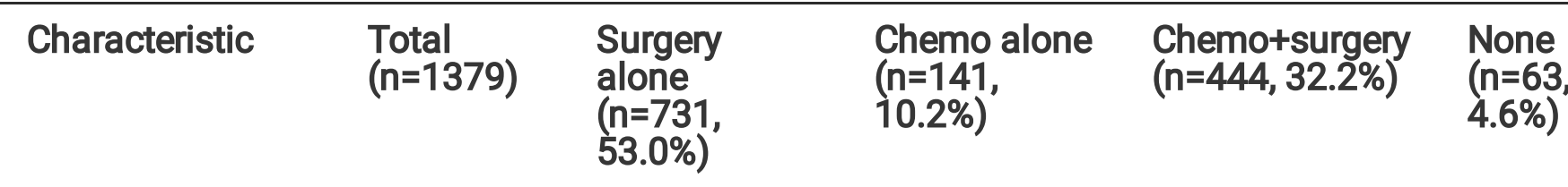

Age group, years,

$\%$

$\begin{array}{llllll}65-74 & 806(58.4) & 425(52.7) & 82(10.2) & 274(34.0) & 25(3.1) \\ \geq 75 & 573(41.6) & 306(53.4) & 59(10.3) & 170(29.7) & 38(6.6)\end{array}$

Race, \%

$\begin{array}{llllll}\text { White } & 930(67.4) & 503(54.1) & 92(9.9) & 289(31.1) & 46(4.9) \\ \text { Non-White } & 449(32.6) & 228(50.8) & 49(10.9) & 155(34.5) & 17(3.8)\end{array}$

Gender, \%

$\begin{array}{llllll}\text { Male } & 655(47.5) & 323(49.3) & 78(11.9) & 224(34.2) & 30(4.6) \\ \text { Female } & 724(52.5) & 408(56.4) & 63(8.7) & 220(30.4) & 33(4.6)\end{array}$

Marital status, \%

$\begin{array}{llllll}\text { Married } & 794(57.6) & 403(50.8) & 83(10.5) & 277(34.9) & 31(3.9) \\ \text { Unmarried } & 529(38.2) & 302(57.1) & 51(9.6) & 148(28.0) & 28(5.3) \\ \text { Unknown } & 56(4.1) & 26(46.4) & 7(12.5) & 19(33.9) & 4(7.1)\end{array}$

Insurance status,

$\%$

\begin{tabular}{llllll} 
Insured & $\begin{array}{l}1337 \\
(97.0)\end{array}$ & $709(53.0)$ & $133(9.9)$ & $435(32.5)$ & $60(4.5)$ \\
Uninsured & $42(3.0)$ & $22(52.4)$ & $8(19.0)$ & $9(21.4)$ & $3(7.1)$ \\
\hline
\end{tabular}

Location, \%

\begin{tabular}{llllll} 
Stomach & $968(70.2)$ & $551(56.9)$ & $93(9.6)$ & $273(28.2)$ & $51(5.3)$ \\
\hline Small intestine & $363(26.3)$ & $170(46.8)$ & $23(6.3)$ & $165(45.5)$ & $5(1.4)$ \\
\hline Others $^{1}$ & $48(3.5)$ & $10(20.8)$ & $25(52.1)$ & $6(12.5)$ & $7(14.6)$
\end{tabular}

T stage, $\%$

\begin{tabular}{|cccccc|}
\hline T1 & $129(9.4)$ & $105(81.4)$ & $5(3.9)$ & $5(3.9)$ & $14(10.9)$ \\
T2 & $487(35.3)$ & $353(72.5)$ & $30(6.2)$ & $84(17.2)$ & $20(4.1)$ \\
\hline T3 & $441(32.0)$ & $189(42.9)$ & $53(12.0)$ & $184(41.7)$ & $15(3.4)$
\end{tabular}




\begin{tabular}{|c|c|c|c|c|c|}
\hline T4 & $322(23.4)$ & $84(26.1)$ & $53(16.5)$ & $171(53.1)$ & $14(4.3)$ \\
\hline \multicolumn{6}{|l|}{ N stage, \% } \\
\hline NO & $\begin{array}{l}1330 \\
(96.4)\end{array}$ & 723 (54.4) & $125(9.4)$ & 421 (31.7) & $61(4.6)$ \\
\hline N1 & 49 (3.6) & 8 (16.3) & $16(32.7)$ & $23(46.9)$ & $2(4.1)$ \\
\hline \multicolumn{6}{|l|}{ M stage, \% } \\
\hline MO & $\begin{array}{l}1194 \\
(86.6)\end{array}$ & 699 (58.5) & $82(6.9)$ & 361 (30.2) & $52(4.4)$ \\
\hline M1 & 185 (13.3) & 32 (17.3) & 59 (31.9) & $83(44.9)$ & $11(5.9)$ \\
\hline \multicolumn{6}{|c|}{ Mitotic index, \% } \\
\hline$\leq 5 / 50$ HPFs & $\begin{array}{l}1010 \\
(73.2)\end{array}$ & $626(62.0)$ & $73(7.2)$ & $266(26.3)$ & $45(4.5)$ \\
\hline > 5/50 HPFs & $369(26.8)$ & 105 (28.5) & 68 (18.4) & 178 (48.2) & $18(4.9)$ \\
\hline \multicolumn{6}{|l|}{ Grade, \% } \\
\hline Grade I & 329 (23.9) & 254 (77.2) & $3(0.9)$ & 70 (21.3) & $2(0.6)$ \\
\hline Grade II & $196(14.2)$ & $102(52.0)$ & $6(3.1)$ & $86(43.9)$ & $2(1.0)$ \\
\hline Grade III & $65(4.7)$ & $21(32.3)$ & $4(6.2)$ & 37 (56.9) & $3(4.6)$ \\
\hline Grade IV & $98(7.1)$ & 35 (35.7) & $4(4.1)$ & $57(58.2)$ & $2(2.0)$ \\
\hline Unknown & $691(50.1)$ & 319 (46.2) & $124(17.9)$ & $194(28.1)$ & $54(7.8)$ \\
\hline \multicolumn{6}{|l|}{ AJCC, \% } \\
\hline I & 697 (50.5) & $520(74.6)$ & $35(5.0)$ & $105(15.1)$ & $37(5.3)$ \\
\hline II & $242(17.5)$ & $98(40.5)$ & $19(7.9)$ & $117(48.3)$ & $8(3.3)$ \\
\hline III & $229(16.6)$ & 75 (32.8) & $23(10.0)$ & $125(54.6)$ & $6(2.6)$ \\
\hline IV & $211(15.3)$ & $38(18.0)$ & $64(30.3)$ & $97(46.0)$ & $12(5.7)$ \\
\hline \multicolumn{6}{|c|}{ Notes: ${ }^{1}$ Including colorectum, esophagus, peritoneum or retroperitoneum, appendix. } \\
\hline
\end{tabular}


Table 2

Polytomous logistic regression for each treatment group (vs. surgery alone) as the dependent variable of interest.

\begin{tabular}{|llllll} 
Characteristic & $\begin{array}{l}\text { No treatment } \\
\text { vs. Surgery } \\
\text { alone, OR }(\mathrm{Cl})\end{array}$ & Pvalue & $\begin{array}{l}\text { Surgery + } \\
\text { chemo vs. } \\
\text { Surgery alone, } \\
\text { OR (Cl) }\end{array}$ & $\begin{array}{l}\text { Pvalue } \\
\text { Chemo } \\
\text { alone vs. } \\
\text { Surgery } \\
\text { alone, OR } \\
\text { (Cl) }\end{array}$ & Pvalue \\
\end{tabular}

Age group,

years, \%

\begin{tabular}{|c|c|c|c|c|c|}
\hline 65-74 & $\begin{array}{l}0.415(0.235- \\
0.734)\end{array}$ & 0.003 & $\begin{array}{l}1.167(0.882- \\
1.545)\end{array}$ & 0.281 & $\begin{array}{l}0.961 \\
(0.616- \\
1.499)\end{array}$ \\
\hline$\geq 75$ & Ref & & Ref & & Ref \\
\hline
\end{tabular}

Race, \%

White

Ref

Ref

Ref

Non-White

$0.794(0.428-$
$1.472)$

0.464

1.304 (0.976 -

0.073

1.402

(0.891 -

0.144

2.207)

Gender, \%

\begin{tabular}{lllllll} 
Male & Ref & \multicolumn{2}{c}{ Ref } & Ref & \\
Female & $0.869(0.483-$ & 0.640 & $1.046(0.788-$ & 0.756 & 0.779 & 0.285 \\
& $1.563)$ & & $1.389)$ & & $(0.494-$ & \\
& & & & $1.231)$ &
\end{tabular}

Marital

status, \%

Married

Ref

Ref

Ref

Unmarried

$1.115(0.605-$

0.727

0.698 (0.515 -

0.020

0.906

(0.557 -

0.689

2.057)

$0.945)$

1.471)

Unknown

$1.852(0.542-$

6.326)

0.326

$1.272(0.645$

2.509)

0.487

1.907

(0.697 -

0.208

5.215 )

Insurance

status, $\%$

Insured

Ref

Ref

Ref

Uninsured

$1.555(0.420$ -

0.508

0.494 (0.198 -

0.132

1.347

(0.478 -

0.573

3.800 )

Location, \% 


\begin{tabular}{|c|c|c|c|c|c|c|}
\hline Stomach & $\begin{array}{l}0.133(0.042- \\
0.426)\end{array}$ & 0.001 & $\begin{array}{l}0.899(0.293- \\
2.759)\end{array}$ & 0.852 & $\begin{array}{l}0.084 \\
(0.031- \\
0.224)\end{array}$ & 0.000 \\
\hline $\begin{array}{l}\text { Small } \\
\text { intestine }\end{array}$ & $\begin{array}{l}0.038(0.009- \\
0.159)\end{array}$ & 0.000 & $\begin{array}{l}1.374(0.441 \text { - } \\
4.286)\end{array}$ & 0.584 & $\begin{array}{l}0.050 \\
(0.017- \\
0.146)\end{array}$ & 0.000 \\
\hline Others $^{1}$ & Ref & & Ref & & Ref & \\
\hline \multicolumn{7}{|l|}{ T stage, $\%$} \\
\hline T1 & $\begin{array}{l}1.767(0.700- \\
4.462)\end{array}$ & 0.228 & $\begin{array}{l}0.044(0.017- \\
0.113)\end{array}$ & 0.000 & $\begin{array}{l}0.229 \\
(0.077- \\
0.679)\end{array}$ & 0.008 \\
\hline T2 & $\begin{array}{l}0.414(0.185- \\
0.927)\end{array}$ & 0.032 & $\begin{array}{l}0.183(0.125- \\
0.268)\end{array}$ & 0.000 & $\begin{array}{l}0.255 \\
(0.139- \\
0.467)\end{array}$ & 0.000 \\
\hline T3 & $\begin{array}{l}0.556(0.243- \\
1.271)\end{array}$ & 0.164 & $\begin{array}{l}0.627(0.440- \\
0.893)\end{array}$ & 0.010 & $\begin{array}{l}0.717 \\
(0.414- \\
1.241)\end{array}$ & 0.235 \\
\hline T4 & Ref & & Ref & & Ref & \\
\hline \multicolumn{7}{|l|}{ N stage, \% } \\
\hline NO & $\begin{array}{l}0.451(0.086- \\
2.368)\end{array}$ & 0.346 & $\begin{array}{l}0.454(0.188 \text { - } \\
1.097)\end{array}$ & 0.079 & $\begin{array}{l}0.254 \\
(0.089- \\
0.728)\end{array}$ & 0.011 \\
\hline $\mathrm{N} 1$ & Ref & & Ref & & Ref & \\
\hline \multicolumn{7}{|l|}{ M stage, \% } \\
\hline MO & $\begin{array}{l}0.316(0.132- \\
0.755)\end{array}$ & 0.010 & $\begin{array}{l}0.510(0.317- \\
0.820)\end{array}$ & 0.005 & $\begin{array}{l}0.141 \\
(0.078- \\
0.255)\end{array}$ & 0.000 \\
\hline M1 & Ref & & Ref & & Ref & \\
\hline \multicolumn{7}{|l|}{$\begin{array}{l}\text { Mitotic index, } \\
\%\end{array}$} \\
\hline$\leq 5 / 50$ HPFs & $\begin{array}{l}0.603(0.305- \\
1.195)\end{array}$ & 0.147 & $\begin{array}{l}0.492(0.349- \\
0.694)\end{array}$ & 0.000 & $\begin{array}{l}0.429 \\
(0.262- \\
0.700)\end{array}$ & 0.001 \\
\hline > 5/50 HPFs & Ref & & Ref & & Ref & \\
\hline \multicolumn{7}{|l|}{ Grade, \% } \\
\hline Grade I & Ref & & Ref & & Ref & \\
\hline Grade II & $\begin{array}{l}1.971(0.265- \\
14.663)\end{array}$ & 0.508 & $\begin{array}{l}1.928(1.226- \\
3.031)\end{array}$ & 0.004 & $\begin{array}{l}2.505 \\
(0.578- \\
10.851)\end{array}$ & 0.219 \\
\hline
\end{tabular}




\begin{tabular}{|c|c|c|c|c|c|c|}
\hline Grade III & $\begin{array}{l}11.711(1.716- \\
79.937)\end{array}$ & 0.012 & $\begin{array}{l}2.321(1.163- \\
4.632)\end{array}$ & 0.017 & $\begin{array}{l}3.584 \\
(0.675- \\
19.035)\end{array}$ & 0.134 \\
\hline Grade IV & $\begin{array}{l}3.262(0.395- \\
26.920)\end{array}$ & 0.272 & $\begin{array}{l}1.595(0.871- \\
2.923)\end{array}$ & 0.131 & $\begin{array}{l}1.104 \\
(0.205- \\
5.947)\end{array}$ & 0.908 \\
\hline Unknown & $\begin{array}{l}19.219(4.515- \\
81.806)\end{array}$ & 0.000 & $\begin{array}{l}1.541(1.073- \\
2.211)\end{array}$ & 0.019 & $\begin{array}{l}17.639 \\
(5.371- \\
57.933)\end{array}$ & 0.000 \\
\hline
\end{tabular}

Notes: ${ }^{1}$ Including colorectum, esophagus, peritoneum or retroperitoneum, appendix.

Abbreviations: Chemo = Chemotherapy; HPFs = high-power fields; $\mathrm{OR}=$ odds ratio; $\mathrm{Cl}=$ confidence interval.

Table 3

Adjusted hazard ratio for different treatment in elderly patients according age groups.

\begin{tabular}{|lllll}
\hline Treatment & \multicolumn{6}{l}{$\mathbf{6 5 - 7 4 \text { years }}$} & & $\mathbf{2 7 5}$ years & \\
\cline { 2 - 5 } & HR $(\mathbf{9 5 \%} \mathrm{Cl})$ & P value & HR $(\mathbf{9 5 \%} \mathrm{Cl})$ & P value \\
\hline Surgery alone & Ref & & Ref & \\
\hline Chemotherapy alone & $2.773(1.451-5.299)$ & 0.002 & $1.136(0.673-1.917)$ & 0.634 \\
\hline Surgery + Chemotherapy & $0.723(0.440-1.189)$ & 0.202 & $0.690(0.473-1.006)$ & 0.054 \\
\hline No therapy & $1.582(0.532-4.698)$ & 0.409 & $2.075(1.136-3.793)$ & 0.018 \\
\hline Abbreviations: HR = Hazard Ratio; $95 \% \mathrm{Cl}=95 \%$ Confidence Interval. & \\
\hline
\end{tabular}


Table 4

Univariate and multivariate analysis of OS in the training set.

\section{Characteristic}

Univariate analysis

$\mathrm{HR}(95 \% \mathrm{Cl})$
Multivariate analysis

p value $\quad H R(95 \% \mathrm{Cl})$ $\mathrm{p}$ value

Age group, years

$\begin{array}{lllll}65-74 & \text { Ref } & \text { Ref } & \\ \geq 75 & 3.035(2.252-4.090) & 0.000 & 3.141(2.300-4.289) & 0.000\end{array}$

Race

White

Non-White

Gender

Male

Female

Marital status

Married

Unmarried

Unknown

Insurance status

Insured

Uninsured

Location

Stomach

Small intestine

Others $^{1}$

T stage
$\mathrm{T} 1$

T2

T3
Ref

$0.836(0.604-1.157)$

Ref

$0.658(0.494-0.876)$

0.004

Ref

0.281

$1.099(0.780-1.548)$

0.589

Ref

$0.522(0.377-0.723) \quad 0.000$

0.759

Ref

$1.546(1.157-2.064) \quad 0.003 \quad 1.711(1.231-2.378) \quad 0.001$

$0.815(0.331-2.003)$

0.655

$1.154(0.462-2.883)$

Ref

Ref

$2.683(1.458-4.937)$

0.002

$2.395(1.254-4.577)$

Ref
0.008

Ref

Ref

$1.680(1.244-2.269)$

0.001

$1.681(1.214-2.329)$

0.002

$2.578(1.418-4.684)$

0.002

$1.868(0.973-3.587)$

0.061
Ref

$0.605(0.349-1.050)$

$0.887(0.523-1.505)$
0.074

$0.501(0.285-0.881)$

$0.657 \quad 0.646(0.365-1.144)$
0.016

0.134 


\begin{tabular}{|c|c|c|c|c|}
\hline T4 & $1.653(0.985-2.775)$ & 0.057 & $1.058(0.587-1.907)$ & 0.851 \\
\hline \multicolumn{5}{|l|}{$\mathrm{N}$ stage } \\
\hline NO & \multicolumn{2}{|l|}{ Ref } & \multicolumn{2}{|l|}{ Ref } \\
\hline N1 & $1.713(0.905-3.244)$ & 0.098 & $0.974(0.497-1.908)$ & 0.938 \\
\hline \multicolumn{5}{|l|}{ M stage } \\
\hline MO & \multicolumn{2}{|l|}{ Ref } & \multicolumn{2}{|l|}{ Ref } \\
\hline M1 & $2.715(1.964$ - 3.755$)$ & 0.000 & $1.540(1.051-2.256)$ & 0.027 \\
\hline \multicolumn{5}{|l|}{ Mitotic index } \\
\hline$\leq 5 / 50 \mathrm{HPFs}$ & \multicolumn{2}{|l|}{ Ref } & \multicolumn{2}{|l|}{ Ref } \\
\hline > 5/50 HPFs & $2.311(1.734-3.081)$ & 0.000 & $1.847(1.295-2.634)$ & 0.001 \\
\hline \multicolumn{5}{|l|}{ Grade } \\
\hline Grade I & \multicolumn{2}{|l|}{ Ref } & \multicolumn{2}{|l|}{ Ref } \\
\hline Grade II & $1.136(0.645-2.002)$ & 0.658 & $0.707(0.384-1.301)$ & 0.265 \\
\hline Grade III & $2.762(1.465-5.211)$ & 0.002 & $1.169(0.571-2.393)$ & 0.669 \\
\hline Grade IV & $3.135(1.863-5.274)$ & 0.000 & $1.584(0.848-2.959)$ & 0.149 \\
\hline Unknown & $1.356(0.900-2.043)$ & 0.146 & $0.744(0.472-1.173)$ & 0.203 \\
\hline \multicolumn{5}{|l|}{ Treatment } \\
\hline Surgery alone & \multicolumn{2}{|l|}{ Ref } & \multicolumn{2}{|l|}{ Ref } \\
\hline Chemotherapy only & $2.634(1.751-3.960)$ & 0.000 & $1.659(1.009-2.727)$ & 0.046 \\
\hline Surgery + Chemotherapy & $1.116(0.797-1.563)$ & 0.522 & $0.725(0.498-1.055)$ & 0.093 \\
\hline No therapy & $2.548(1.493-4.349)$ & 0.001 & $2.424(1.353-4.343)$ & 0.003 \\
\hline \multicolumn{5}{|c|}{ NNotes: ${ }^{1}$ Including colorectum, esophagus, peritoneum or retroperitoneum, appendix. } \\
\hline \multicolumn{5}{|c|}{$\begin{array}{l}\text { Abbreviations: HPFs = high-power fields; HR = Hazard Ratio; } 95 \% \mathrm{Cl}=95 \% \text { Confidence Interval; OS = } \\
\text { overall survival. }\end{array}$} \\
\hline
\end{tabular}

\section{Figures}




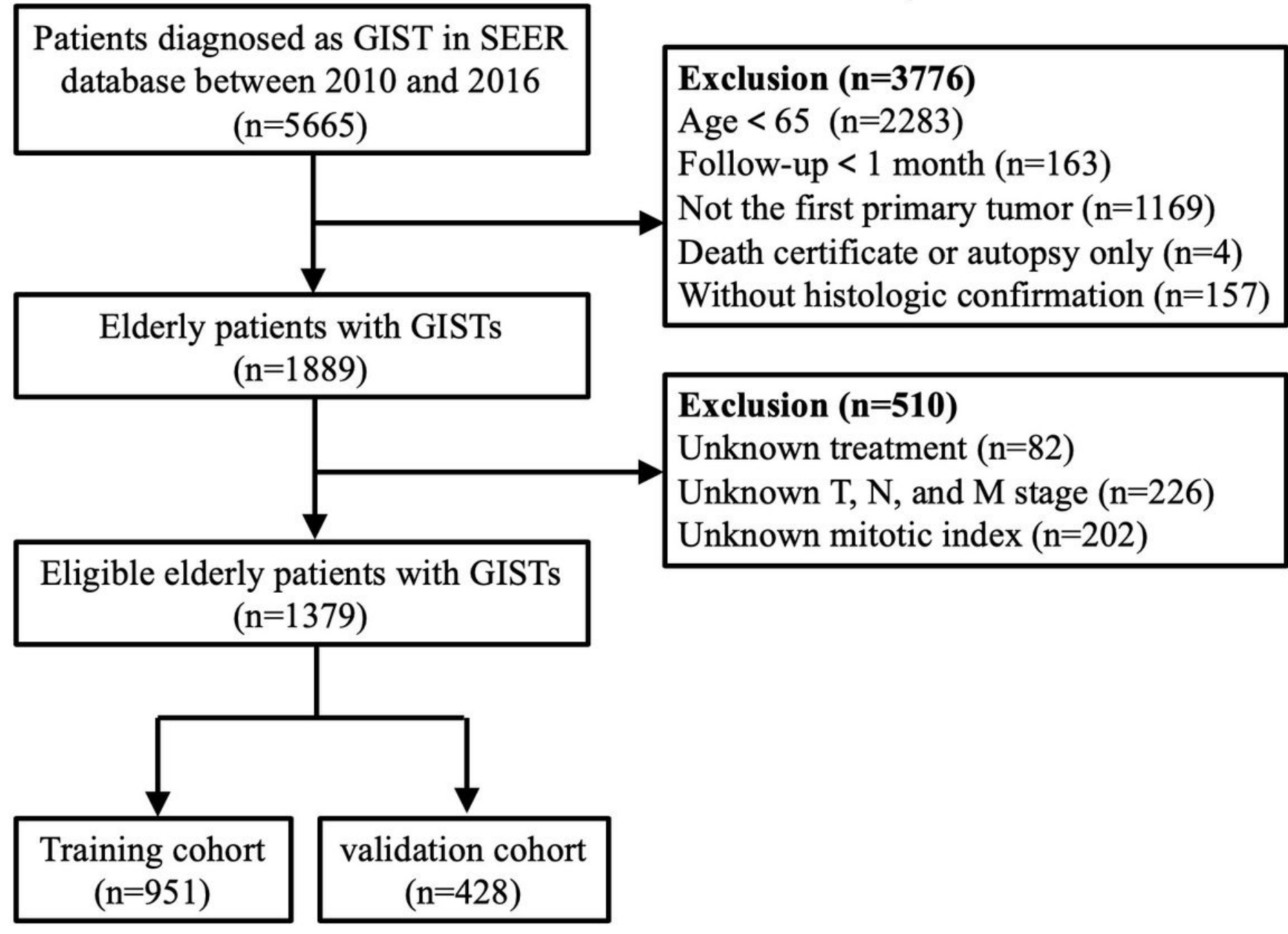

Figure 1

Flow diagram of eligible elderly patients diagnosed with gastrointestinal stromal tumors (GISTs). 


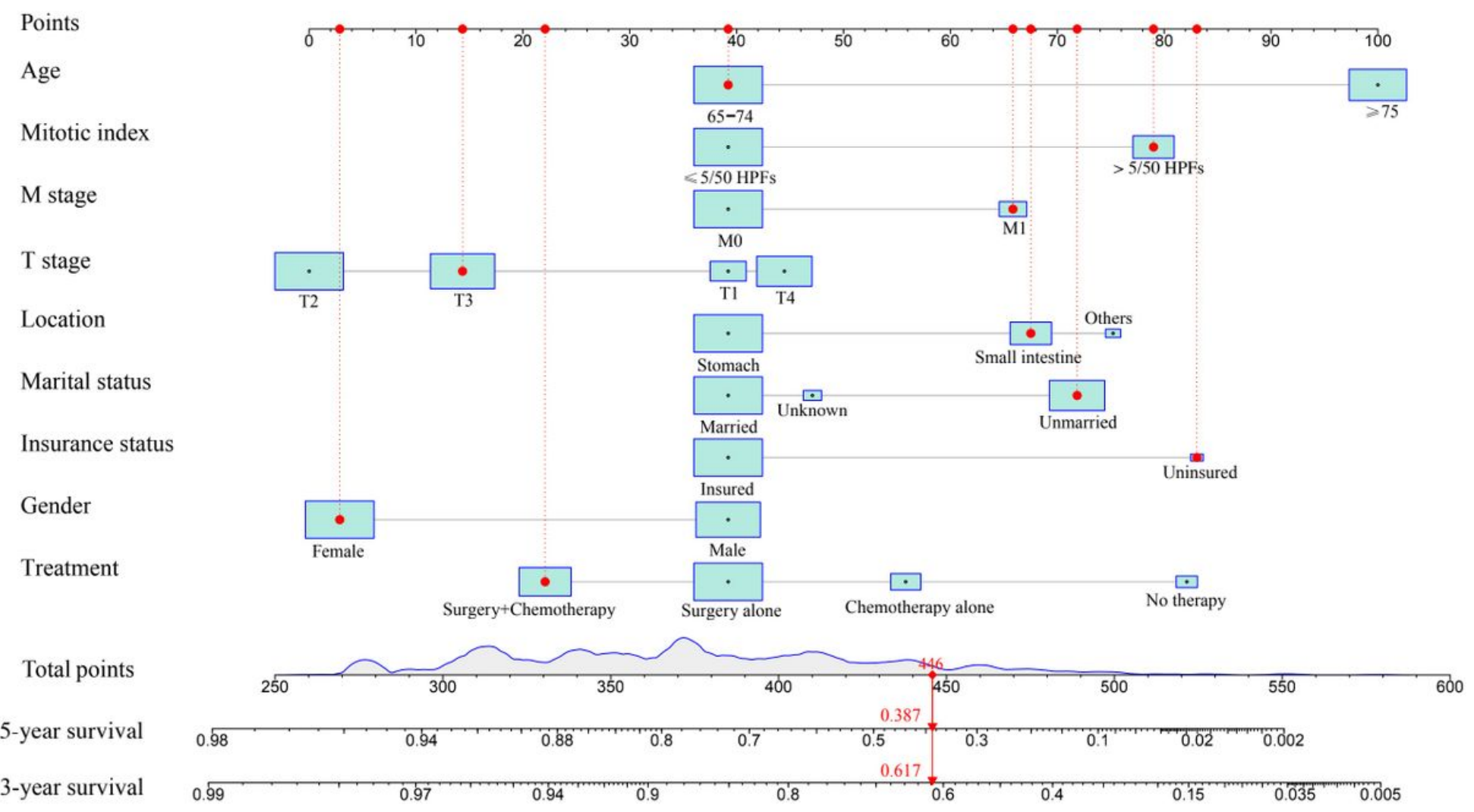

Figure 2

Nomogram for predicting the 3-, and 5-year overall survival of elderly GIST patients. Each category of the prognostic variables is assigned a score on the Points scale. The sum of these scores is located on the Total points scale and a line is drawn downward to determine the specific probability of 3-and 5-year overall survival. 
A

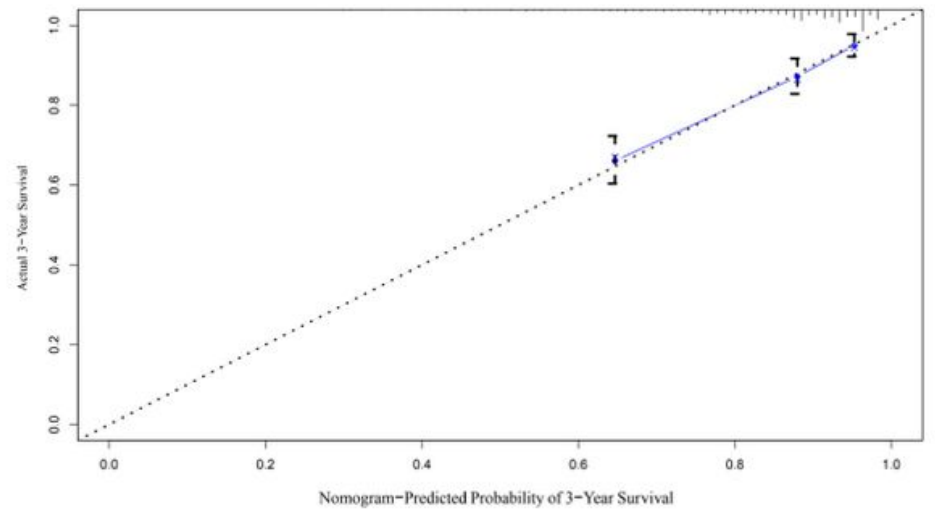

C

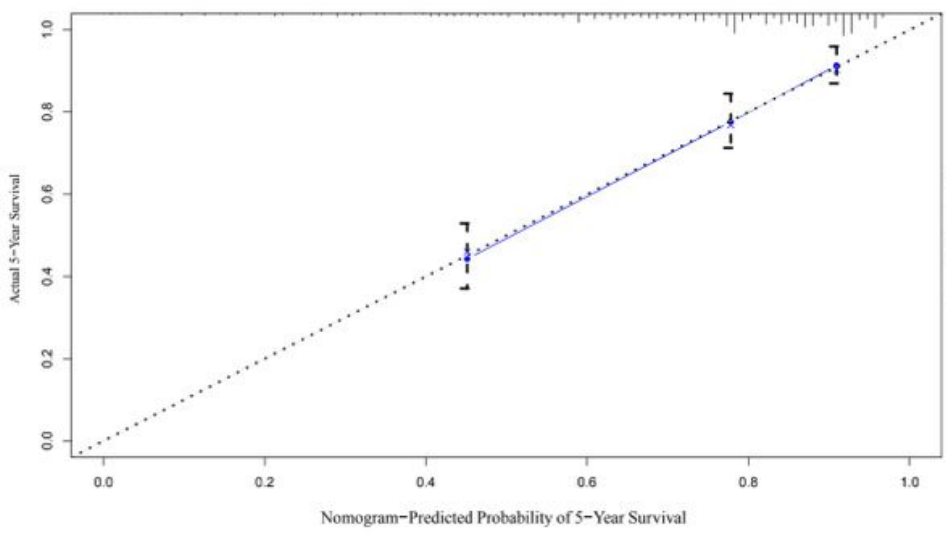

B

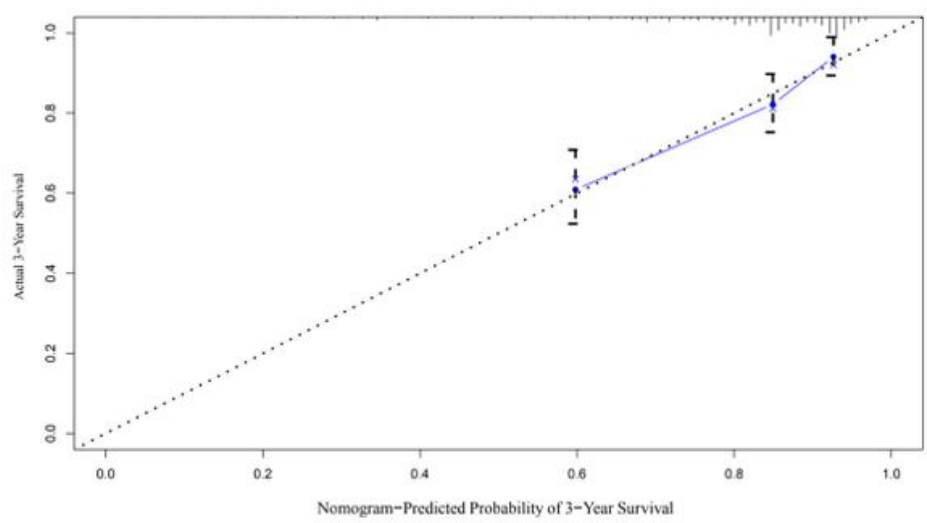

$\mathrm{D}$

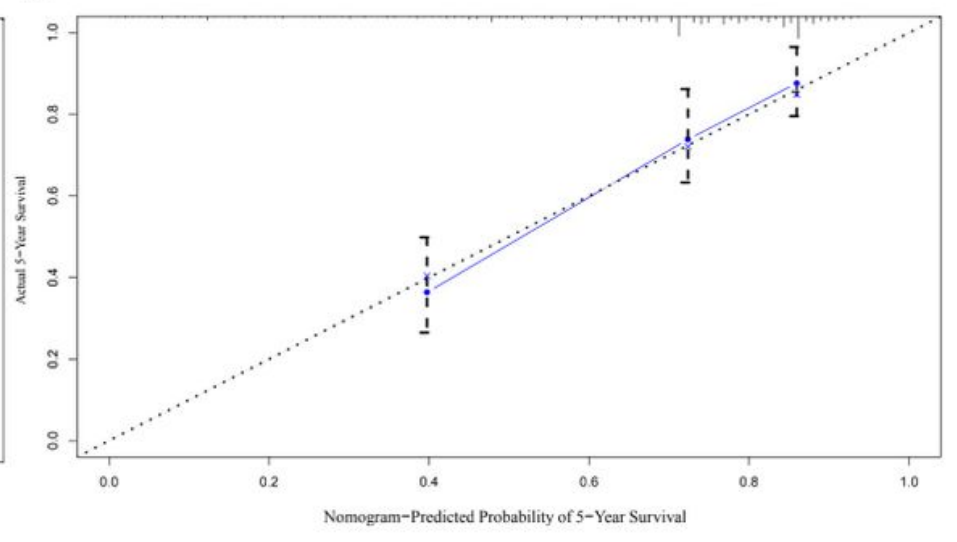

\section{Figure 3}

The calibration curves for predictions of overall survival in elderly GISTs patients. (A) Calibration plots of 3-year OS in training set. (B) Calibration plots of 3-year OS in validation set. (C) Calibration plots of 5-year OS in training set. (D) Calibration plots of 5-year OS in validation set. The dashed line represents perfect agreement between the nomogram-predicted probability (x-axis) and the actual probability, calculated from a Kaplan-Meier analysis (y-axis). OS = overall survival. 

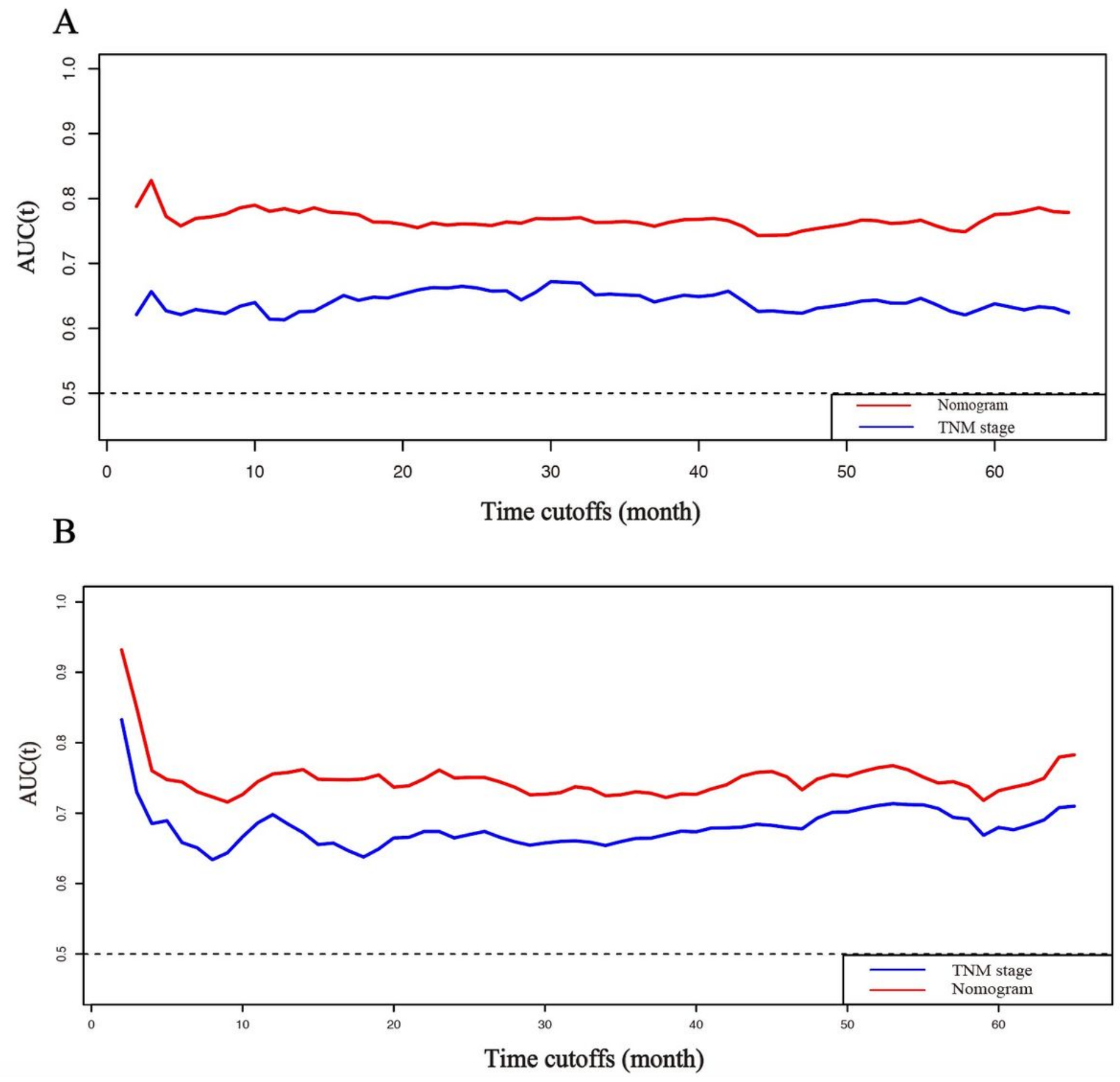

Figure 4

Area under the curve (AUC) models for comparing the predictive ability between nomograms and AJCC TNM stage. (A) The OS nomogram and AJCC TNM stage in the training set. (B) The OS nomogram and AJCC TNM stage in the validation set. AUC was calculated for every month from the first to the 60th month. OS = overall survival, AJCC $=$ American Joint Committee on Cancer. 
A

Strata + Low risk + Middle risk + High risk

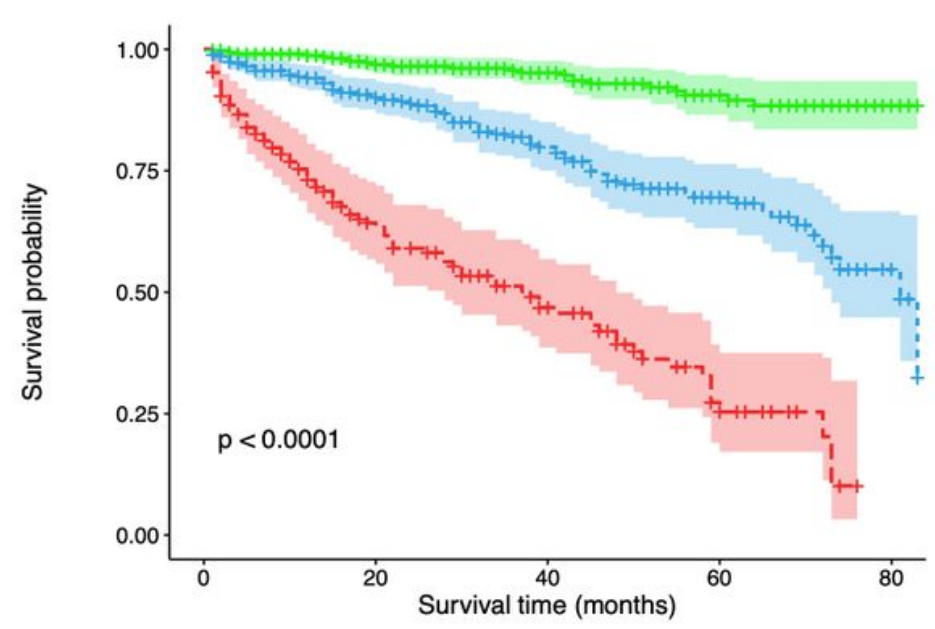

Number at risk
B

Strata + Low risk +- Middle risk +- High risk

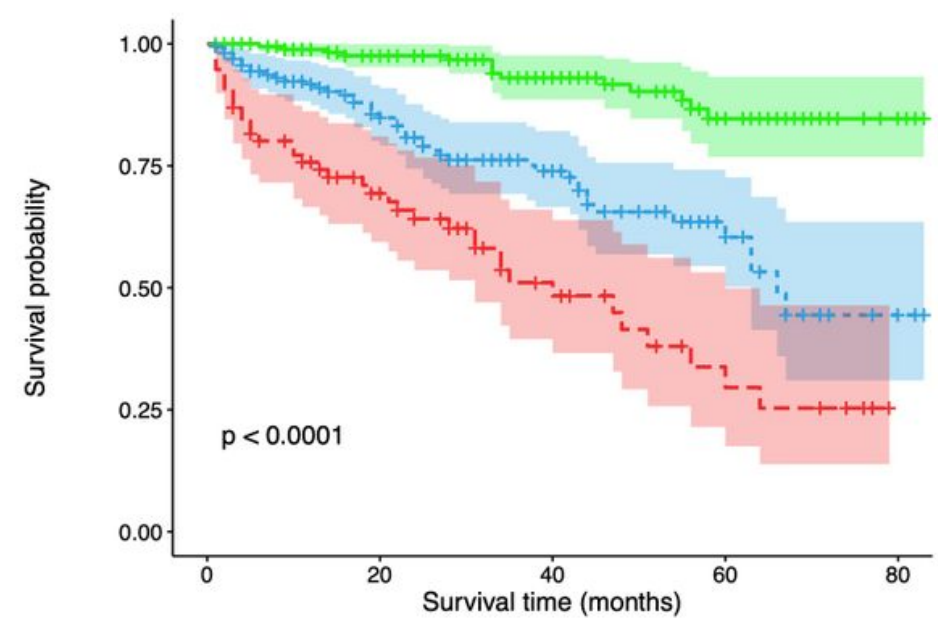
Number at risk

\section{Figure 5}

Kaplan-Meier survival curves of nomogram.(A) In the training cohort. (B) In the validation cohort.

\section{Supplementary Files}

This is a list of supplementary files associated with this preprint. Click to download.

- Supplementarydata.docx 